
Motrivivência
v. 28 ,
n. 47 ,
p. $160-176$, maio/2016

\title{
PERCEPÇÕES DOS PROFESSORES ACERCA DA EDUCAÇÃO FíSICA: um estudo de caso
}

Antonino Manuel Pereira'

Corla Silva ${ }^{2}$

Cláudia Pinheiro 3

\begin{abstract}
RESUMO
Apesar do elevado potencial para desenvolvimento dos jovens, a Educação Física tem enfrentado diversos constrangimentos em vários países. Nesse sentido, este estudo pretendeu conhecer as representações de professores acerca do estado atual da EF numa cidade da região centro de Portugal. O campo de estudo foi composto por 10 docentes, a lecionar em escolas públicas do concelho de Viseu, aos quais foram realizadas entrevistas semiestruturadas. Os dados evidenciam que os alunos têm vindo a atribuir uma menor importância à EF enquanto os pais a valorizam mais. Relativamente aos programas, referem que diversas vezes são ignorados os interesses dos alunos, devem ser menos extensos e proporcionar novas modalidades relacionadas com o meio sociocultural. Defendem que a avaliação atualmente é adequada e no futuro deverá evidenciar mais o empenhamento do aluno.
\end{abstract}

Palavras-chave: Perceções; Educação Física; Professores; Estudo de Caso

1 Docente na Escola Superior de Educação - Instituto Politécnico de Viseu. Portugal. E-mail: apereira@esev.ipv.pt 2 Docente no Agrupamento de Escolas de Celorico da Beira. Celorico/Portugal. E-mail: csbsilva759@hotmail.com 3 Docente no Instituto Universitário da Maia. Portugal. E-mail: mpinheiro@docentes.ismai.pt 


\section{INTRODUÇÃO}

São vários os autores que referem que a Edução Física (EF) tem o potencial para contribuir para o desenvolvimento dos jovens no âmbito dos domínios físico, social, afetivo, cognitivo e dos estilos de vida (BAILEY, 2006).

$\mathrm{O}$ valor da EF tem, também, sido expresso em vários documentos da Comissão Europeia (EUROPEAN COMMISSION/ EACEA/EURYDICE, 2013). Entre as suas potencialidades são sublinhadas a saúde, o desenvolvimento global das crianças e jovens e a inclusão social. Esta disciplina faz parte de todas as estruturas centrais do currículo, e é obrigatória no ensino primário e no ensino secundário em toda a Europa.

Apesar da sua importância, em Portugal, não existe um reconhecimento efetivo da disciplina de EF como essencial para o crescimento e desenvolvimento das crianças e jovens, vigorando por vezes, ainda a ideia de que a $\mathrm{EF}$, apenas possa ter a função de recreio e entretenimento dos alunos (CORTESÃO, 2010).

Este entendimento vai ao encontro das várias conceções que podemos encontrar acerca desta disciplina. Assim, Cunha (2013), ao fazer uma análise à Educação Física na Europa, refere que existem, pelo menos, seis grandes conceções: psicomotricidade; desportivista; educação desportiva; especialização precoce; voluntariado; "novos" movimentos. Por sua vez, na pesquisa bibliográfica efetuada por Santos, Marques e Martins (2014), foram identificadas diferentes perspetivas da disciplina de Educação Física, a saber, biomédica, desportiva e educacional.

Estudos realizados nos Estados Unidos da América, em Inglaterra e na Austrália indicam que a EF está em declínio em muitas escolas. O tempo que lhe é atribuído ou é insuficiente, ou foi reduzido com o objetivo de atribuir mais tempo a outras áreas de aprendizagem supostamente consideradas essenciais ou mais importantes para a formação dos alunos (HARDMAN, 2008).

No que concerne ao Brasil, e de acordo com alguns autores, existe um conjunto de condicionalismos que colocam a Educação Física em crise. Assim, surgiram novas maneiras de representar a educação e a sociedade as quais colocam desafios para a permanência da EF nas escolas, ou seja, a sua presença não está garantida, podendo mesmo ser excluída das práticas escolares (VAGO, 1999). Por sua vez, Betti e Zuliani (2002) afirmam que os jovens apesar de valorizarem muito as práticas corporais realizadas fora da escola, questionam a "atual prática pedagógica da Educação Física escolar não vendo mais significado na disciplina, desinteressam-se e forçam situações de dispensa"(p.54).

De acordo com Cunha (2013), essa crise pode ser também acentuada pela existência de, pelo menos, onze grandes conceções de EF (Conceções preditivas: aulas abertas; atividade física para a promoção da saúde; construtivista-interacionista; crítico-emancipadora e didática comunicativa; crítico-superadora; desenvolvimentista; educação física plural. Conceções não preditivas: humanista; psicomotricista; sistêmica), as quais defendem métodos e objetos de intervenção pedagógica muito particulares, podendo ter implicações práticas no ensino da disciplina.

De acordo com dados da Comissão Europeia, no que se refere ao número de horas anuais/semanais atribuídas à $E F$, e quando se compara com outras disciplinas, 
esse número é relativamente baixo. Em geral, corresponde a cerca de metade do tempo dedicado à Matemática (EUROPEAN COMMISSION/EACEA/EURYDICE, 2013).

Algumas investigações demonstram que a pedagogia tradicional predomina, verificando-se aspetos como a exercitação mecânica, a competição exacerbada, a valorização das competências individuais e a preocupação com o desempenho final (NETO; SILVA; MIRANDA, 2013).

No que refere a Portugal, nos últimos anos têm surgido medidas governamentais algo preocupantes. Assim, de acordo com o decreto-lei no 139/2012, de 5 de julho, promove-se de forma injustificada e sem qualquer base científica uma redução horária de uma disciplina que poderá contribuir para a saúde da população infantil e juvenil portuguesa. Isto num contexto em que o país revela a segunda maior taxa de predomínio de obesidade e sobrepeso da Europa, e uma das mais baixas taxas de prevalência de atividade física. Consequentemente, fomenta o desenvolvimento de um dos maiores flagelos do século XXI, o sedentarismo, e compromete o imprescindível desenvolvimento de hábitos de vida saudável na população portuguesa (CNAPEF; SPEF, 2012).

Com este diploma, a classificação da disciplina de EF, no ensino secundário, deixa de contar para o apuramento da média final dos alunos. Esta medida implica um retrocesso e irá conduzir a uma enorme desvalorização desta área (LOURENÇO, 2012; ROCHA, 2012).

Face a estes desenvolvimentos, é importante conhecer o estado atual da EF em Portugal. Para tal, é imprescindível auscultar a opinião dos professores, nomeadamente: Qual é, na sua opinião, a importância que os alunos e pais e encarregados de educação atribuem a esta disciplina? Quais são os principais constrangimentos ao nível dos conteúdos programáticos e da avaliação que a disciplina apresenta?

Assim este estudo, de carater exploratório e enquadrado numa perspetiva interpretativa (DENZIN; LINCOLN, 2008), tem como objetivos: a) conhecer a importância atribuída à disciplina de EF pelos alunos e encarregados de educação, de acordo com as representações dos professores de EF; b) caracterizar a atualidade dos conteúdos programáticos e a avaliação dos alunos; c) conhecer sugestões que possam contribuir para o enriquecimento dos programas e da avaliação desta disciplina.

A vontade de contribuir para aumentar o conhecimento da realidade existente em Portugal sobre esta temática, bem como caracterizar uma realidade existente na sua região centro interior parece-nos também pertinente.

Por outro lado, são vários os autores que defendem que os professores devem diagnosticar a realidade, reconhecerem as dificuldades e as necessidades da EF (MACPHAIL, 2011), uma vez que tal processo de reflexão poderá desenvolver novas dinâmicas e mudanças benéficas para a promoção da disciplina.

\section{METODOLOGIA}

O campo de estudo foi composto por dez professores de EF, escolhidos de forma aleatória, sendo seis do género masculino e quatro do feminino, com idade compreendida entre os 52 e 58 anos de idade e o tempo de serviço no ensino público entre os 31 e os 40 anos. A formação académica dos nossos entrevistados foi 
obtida na Faculdade de Motricidade Humana - Universidade de Lisboa e na Faculdade de Deporto - Universidade do Porto. Nove possuem licenciatura e um é bacharel. Um deles tem uma pós graduação em gestão do desporto e outro o mestrado em desporto para crianças e jovens. Todos os nossos entrevistados encontram-se no ativo e lecionam a disciplina de EF no Ensino Básico e ou Secundário ${ }^{4}$ em escolas públicas da cidade de Viseu, a qual tem uma população próxima dos 48.000 habitantes, e se situa na região centro interior de Portugal. Viseu pode ser caracterizado como um centro administrativo, de comércio e de serviços e o seu índice de qualidade de vida é um dos mais elevados das cidades portuguesas. De acordo com um estudo realizado pela DECO (Associação Portuguesa para a Defesa do Consumidor), publicado em 2012, Viseu foi eleita pelos portugueses a melhor cidade para viver do país, onde a saúde, a educação, a mobilidade e o meio ambiente proporcionam uma grande harmonia.

Numa primeira fase foi solicitada às escolas implicadas permissão para a realização das entrevistas aos docentes escolhidos. De seguida foi explicado a cada um dos participantes os objetivos do presente estudo garantindo sempre a confidencialidade da informação prestada, obtendo-se assim o seu consentimento informado.

Atendendo aos objetivos deste estudo optamos pela utilização da entrevista semiestruturada (GHIGLIONE; MATALON, 2001), cujo guião (roteiro) foi elaborado a partir de algumas referências bibliográficas
(AZEVEDO, 2007; BENTO, 2004; CRATO, 2010; GRILO, 2007; HARDMAN, 2008; PEREIRA, 2005a; PEREIRA, 2005b). A primeira versão foi submetida a uma análise por peritos. Depois de terem sugerido algumas alterações, um novo guião foi aplicado a dois indivíduos que não faziam parte do grupo de participantes. Após a análise destas entrevistas entendemos ser necessário proceder a alguns ajustamentos, tendo assim surgido a versão final. Este guião centrou-se em torno de questões relativamente abertas sobre a perceção dos docentes sobre: a importância atribuída à EF pelos alunos e pelos progenitores; os programas de $\mathrm{EF}$ nas últimas três décadas e atualmente e a avaliação em EF nas últimas três décadas e atualmente. As entrevistas foram realizadas durante o mês de maio do ano 2014 nos departamentos de Educação Física das escolas onde os docentes exerciam a sua atividade.

Todas as entrevistas foram gravadas e transcritas verbatim. A técnica de tratamento da informação utilizada foi a "Análise de Conteúdo" (BARDIN, 2008), sendo a categorização efetuada a priori. As categorias de análise foram: Importância atribuída à EF; Programas e conteúdos de EF e Avaliação dos alunos na disciplina de EF.

\section{ANÁLISE E INTERPRETAÇÃO DOS RESULTADOS}

\section{Importância atribuída à disciplina de EF}

No que se refere aos alunos, os entrevistados indicam, maioritariamente,

4 De acordo com a Lei $n^{\circ}$ 49/2005 de 30 de Agosto, Lei de Bases do Sistema Educativo, em Portugal o ensino básico tem a duração de 9 anos e compreende três ciclos sequenciais, sendo o $1^{\circ}$ de quatro anos, o $2^{\circ}$ de dois anos e o $3^{\circ}$ de três anos. Ingressam no ensino básico as crianças que completem 6 anos de idade até 15 de Setembro. O Ensino Secundário tem a duração de três anos. 
que eles atribuíam mais importância à disciplina de EF nas últimas décadas do que no presente.

"Na década 80 e 90 os alunos davam mais importância à EF do que dão hoje em dia..." E10 5 .

"Davam muito mais importância do que dão hoje, eram mais empenhados, gostavam muito de praticar a disciplina, muito mais concentrados; nessa altura havia um gosto especial pela EF". E7

Vários estudos em Portugal referindo essa época evidenciavam que os alunos gostavam da disciplina de EF e consideravam importante a sua inclusão no currículo escolar. Isso parece não ter sido influenciado pela condição socioeconómica da família e a localização da escola (FRAGA, 1994; SHIGUNOV; CARREIRO DA COSTA; BRITO, 1993).

Dois dos docentes, no entanto, foram de opinião que os alunos nas três últimas décadas davam pouca importância à disciplina de $E F$, uma vez que esta não apresentava grande influência no currículo dos alunos. Segundo estes docentes, os alunos consideravam as aulas de EF mais no sentido de diversão.

"Não Ihe davam a importância adequa$d a$, porque antigamente a avaliação da disciplina não tinha grande influência no currículo do aluno e também devido aos professores de EF facilitarem ao nível do material escolar" E6.

"Ao longo dessas décadas os alunos consideravam as aulas de EF como aulas de diversão, que serviam para gastar energias" E9.

A EF é, várias vezes, criticada por indivíduos que afirmam que esta serve apenas para recreação e jogar futebol. É fundamental reverter essa imagem tradicional e viciada que a sociedade tem da área da $E F$ (DARIDO; RODRIGUES, 2006), uma vez que esta disciplina proporciona o desenvolvimento de competências fundamentais para a formação das crianças e jovens. Assim, e de acordo com UNESCO (2015), o currículo de uma EF de Qualidade promove a estruturação do pensamento e a expressão de sentimentos. Através da competição e da cooperação os alunos apreciam o papel de regras, dos valores, do jogo limpo (fair play) e aprendem a valorizar o trabalho em equipa. Por outro lado, descobrem como reconhecer e gerir os riscos, a cumprir com as tarefas que lhe são atribuídas e a aceitar a responsabilidade pelos seus comportamentos. Aprendem também formas de como lidar com o sucesso e com o fracasso.

Por outro lado, Betti e Zuliani (2002) referem que num tempo de

rápidas e profundas transformações sociais que repercutem, às vezes de maneira dramática, nas escolas, a Educação Física e seus professores precisam fundamentar-se teoricamente para justificar à comunidade escolar e à própria sociedade o que já sabem fazer, e, estreitando as relações entre teoria e prática pedagógica, inovar, quer dizer, experimentar novos modelos, estratégias, metodologias, conteúdos, para que a Educação Física siga contribuindo para a formação integral das crianças e jovens e para a apropriação crítica da cultura contemporânea (p. 80).

5 Visando assegurar o sigilo das fontes são atribuídos códigos aos entrevistados. 
Atualmente, e de acordo com os entrevistados, os alunos revelam algum desinteresse pela disciplina de EF, sentindo-se mais atraídos por outras atividades nomeadamente as tecnologias da informação e comunicação.

“No presente, os alunos já se dispersam para outras atividades e têm outros interesses ao nível das novas tecnologias" E5.

"Hoje os alunos passam muito tempo em frente aos computadores e sentem-se mais motivados para os jogos virtuais" E8.

Nos nossos dias, existe a necessidade de se dar uma maior atenção às práticas físicas, já que o grande problema da inatividade motora vem aumentando com o avanço tecnológico. A prática de uma atividade física nas idades escolares constitui-se, portanto, como um elemento fundamental para a promoção e preservação da saúde, principalmente numa época em que os jogos virtuais cada vez mais cativam os jovens, levando-os ao sedentarismo (BATISTA, 2001).

Oliveira, Gomes e Bracht (2014) afirmam que no contexto da EF brasileira, a saúde sempre desempenhou um papel muito importante. Porém, essa conceção de saúde, orientada estritamente em princípios biológicos, tem limitado a compreensão e desenvolvimento de ações que observem a integralidade do ser humano.

Nesse sentido, a EF deverá ter uma perspetiva de intervenção mais ampla, já que, de acordo com Betti, Ferraz e Dantas (2011),

os professores de Educação Fisica Escolar, elaboram, implementam e avaliam programas de ensino que tematizam, do ponto de vista didático-pedagógico, as brincadeiras e o jogos, o esportes, as lutas, as ginásticas, as danças, exercícios físicos, atividades rítmicas e etc., com propósitos educacionais explícitos e implícitos, quer dizer, com intenção de influenciar a formação dos sujeitos (p.106).

Por outro lado, e no entender dos inquiridos, atualmente os alunos apresentam-se preocupados com a nota da EF, a qual interfere na média do ensino secundário para a ingressão na faculdade. Importa aqui realçar que as entrevistas deste estudo foram realizadas poucas semanas antes da publicação do Decreto-lei n¹39/2012, de 5 de julho, o qual determina que a classificação da disciplina de EF deixa de contar para o apuramento da média final dos alunos do $12^{\circ}$ ano (ano terminal do ensino secundário).

\footnotetext{
“Atualmente tem-se notado, uma evolução devido ao facto de no ensino secundário, a nota contar para a média" E9.

"Hoje os alunos estão cada vez mais preocupados (...) com a nota que possam ter" E4.
}

Para muitos alunos, o sucesso escolar ainda é visto como fator decisivo para quem passa ou repete o ano escolar. Hoje, vivemos num poderoso desafio na sociedade contemporânea, onde o conhecimento tem um interesse crescente e essencial para o futuro (GRILO, 1999).

É imprescindível adotar expectativas rigorosas para os estudantes. Dentro de limites muito vastos, os alunos adaptam-se às expectativas que deles se formam. Programas e conteúdos ambiciosos e avaliações rigorosas e continuadas trabalham a favor de estudantes melhor preparados. O contrário 
determinará alunos e profissionais incapazes (CRATO, 2006).

Por outro lado,

[...] ao jovem deixa de ser imperativo que ele receba o saber - conhecimento inerte - sendo que, ao invés, se lhe pede que ele seja o construtor do seu próprio saber e do respetivo processo de aquisição - conhecimento activo. Quanto mais activo for o conhecimento, tanto mais facilmente ele poderá viajar para situações novas e complexas (CARNEIRO, 2001, p. 173-174).

No que se refere aos pais e encarregados de educação, os entrevistados afirmaram que nas últimas décadas eles davam, genericamente, pouca importância à disciplina de EF uma vez que a viam direcionada para a diversão e que servia para manter os seus filhos entretidos.

"Antigamente, para os pais, a disciplina de EF era uma disciplina sem interesse" E3.

"Era uma disciplina que não Ihes dizia praticamente nada" E7.

"Os pais viam a EF com uma disciplina lúdica onde os alunos estavam entretidos e ocupados a fazerem coisas de que gostavam" E2.

Apenas dois dos entrevistados mencionaram que alguns pais e encarregados de educação nas últimas décadas já davam alguma valorização a esta disciplina.

"Notou-se que na última década os pais e encarregados de educação começaram a valorizar mais a disciplina de $E F^{\prime \prime} \mathrm{E} 1$.

"Os pais têm vindo a dar cada vez mais importância à $E F^{\prime \prime}$ E6.
Deacordocom estes dados, verifica-se que nos últimos tempos alguns pais e encarregados de educação têm vindo a tomar consciência da importância que a EF assume para o desenvolvimento dos seus filhos.

Devido aos meios de comunicação e à atual valorização que a ciência tem dado à atividade física e desportiva ao nível da saúde, segundo a opinião dos entrevistados, alguns pais e encarregados de educação, começam gradualmente a valorizar esta disciplina, não só pela nota que pode ajudar a elevar a média final de um ano letivo, mas também a aperceber-se da sua importância na saúde e comportamento dos filhos.

"Os pais sentem a necessidade da disciplina de $E F$, até porque hoje os órgãos de comunicação divulgam bastante a importância do exercício e da atividade física" E6.

"Há pais que começam a valorizar esta disciplina devido reconhecer os benefícios da prática física e desportiva na saúde" E9.

"Hoje, os pais estão preocupados com as notas; nesta escola os pais reclamam quando os filhos não têm a nota que gostariam de ter" E2.

Considerando que a maioria das crianças e jovens frequentam a escola, o papel fundamental que esta instituição e a EF podem e devem assumir na promoção de um estilo de vida ativo tem sido amplamente reconhecido por alguns investigadores (BENTO, 2004; CARREIRO DA COSTA, 2010).

A idade escolar, período relativo ao auge da formação da personalidade (embora se dilate ao longo da vida), é a fase onde se aprendem conceitos e regras educativas com maior facilidade. Incrementar a 
educação para a saúde em meio escolar constitui um investimento a longo prazo: por um lado está a estimular uma geração de jovens sadios, por outro, a informação por eles assimilada leva-os a adotar um estilo de vida apropriada afastando-se de comportamentos inapropriados (GONÇALVES; CARVALHO, 2009).

Por outro lado, e de acordo com Betti e Zuliani (2002),

A Educação Física enquanto componente curricular da Educação Básica deve assumir então uma outra tarefa: introduzir e integrar o aluno na cultura corporal de movimento, formando o cidadão que vai produzi-la, reproduzi-la e transformá-la, instrumentalizando-o para usufruir do jogo, do esporte, das atividades rítmicas e dança, das ginásticas e práticas de aptidão física, em benefício da qualidade da vida (p.75).

\section{Os programas e os conteúdos da disciplina de $E F$}

Segundo a opinião de sete entrevistados, nas últimas três décadas não ocorreram melhorias significativas nos programas nem nos conteúdos, uma vez que são praticamente idênticos desde os anos 1980 até agora. Simultaneamente, os professores continuam a lecionar os mesmos conteúdos.

"Não. As áreas são as mesmas, os professores continuam a lecionar os mesmos conteúdos" E1.

"O programa do secundário sempre foi praticamente o mesmo. O programa está um pouco à frente daquilo que conseguimos aplicar nas escolas" E9.

Os Programas Nacionais de Educação Física $[\mathrm{PNEF}]^{6}$ estabelecem indicadores que auxiliam o professor a orientar a sua prática, mas devido à diversidade cultural presente na "escola de massas" e à uniformidade do currículo que João Formosinho classifica de "pronto-a-vestir de tamanho único", torna-se difícil o desenvolvimento de políticas e práticas de diferenciação pedagógica capazes de valorizar a variedade e de lhe responder com sucesso (FERNANDES, 2000).

De acordo com Formosinho e Machado (2009) a escola e os PNEF confrontam-se com a necessidade de se reorganizarem para vencer o desafio de acolher todas as crianças e jovens e assegurarem também uma diferenciação pedagógica.

Note-se, no entanto, que alguns dos entrevistados, verificaram melhorias nos programas reconhecendo-os mais aperfeiçoados.

\begin{abstract}
"Sim, claramente. Houve uma mudança, uma vez que antigamente só havia paticamente os quatro conteúdos nucleares, que tinham a ver com os quatro desportos coletivos" E7.
\end{abstract}

"Sim, tem-se verificado uma melhoria gradual ao longo dessas décadas, os conteúdos mais apropriados, mais seletivos com menos erros" E10.

Os PNEF constituem um documento indispensável para o desenvolvimento da EF. Procuram assegurar a coerência da atividade dos professores e dos alunos entre 
os diferentes anos de escolaridade, entre turmas e entre escolas. Por isso é um documento que os professores devem conhecer muito bem, particularmente a sua filosofia, a sua estrutura e as suas principais características (QUINA, 2009). Efetivamente, os PNEF sofreram alguns ajustes e com uma gestão local dos mesmos, têm permitido encontrar algumas soluções com melhorias significativas que são aplicadas a cada realidade da escola (JACINTO; COMÉDIAS; MIRA;CARVALHO, 2001-b).

De acordo com a opinião de oito entrevistados, os programas e os conteúdos, atualmente, mostram uma falta de adequação aos interesses e motivações dos alunos, porque na maioria das escolas não há a possibilidade de introduzir novas modalidades e os conteúdos são muito técnicos e pouco lúdicos.

"Os alunos querem cada vez mais atividades diferentes daquelas que nós expomos" E4.

“O programa é demasiado extenso" E3.

"A forma como alguns desportos coletivos é apresentada no programa e nas unidades didáticas são muito técnicas, principalmente no ensino básico; eu acho que o aspeto lúdico está um bocado descorado" E6.

De acordo com Bento (1999), assistimos a uma inadequação dos PNEF, que continuam orientados por atividades que muitas vezes ignoram os interesses e motivações dos jovens no tocante a atividades voltadas para a vivência acentuada da corporalidade, do risco, da aventura, da saúde e da ecologia. O conhecimento e a compreensão das motivações e escolhas dos alunos podem ajudar os professores a selecionar os conteúdo e estratégias de desenvolver. Nesse sentido, o estudo desenvolvido por Filho, Tani, Correia e Corrêa (2012) concluiu que as escolhas feitas pelos adolescentes nas aulas de educação física variam em função do ano de escolaridade, idade e sexo.

Por outro lado, muitas aulas de educação física dão importância somente às questões técnicas das práticas desportivas. Sendo as crianças e jovens seres socioculturais, tal opção fragmenta a sua formação integral deixando de lado a questão dos valores, nomeadamente o respeito mútuo, a cooperação e afetividade (GUIMARÃES; PELLINI; ARAUJO; MAZZINI, 2001). A EF, como qualquer outra disciplina, tem responsabilidade na concretização do processo de formação e desenvolvimento de valores e, por essa razão, deverá considerá-lo como parte de seus conteúdos de ensino.

No entanto, para dois dos nossos entrevistados, atualmente o programa e os conteúdos da EF estão mais adequados aos interesses e motivações dos alunos do que antigamente, uma vez que existe uma divisão ajustada dos conteúdos pelos diferentes anos escolares.

"Houve uma adequação, nesta escola já se faz uma divisão ajustada do programa, porque antigamente dávamos todas as modalidades no $5^{\circ}, 6^{\circ}, 7^{\circ}, 8^{\circ} \mathrm{e}$ $9^{\circ}$, atualmente não" E1.

"Penso que na generalidade estão, o problema é que algumas escolas, por exemplo de meios mais rurais, não apresentam tantas condições para abordar determinados conteúdos das modalidades alternativas" E5.

Os PNEF devem assentar numa proposta em que um dos seus pilares 
fundamental é exatamente a possibilidade de adaptação às situações concretas, quer humanas quer materiais, das diferentes escolas (JACINTO; COMÉDIAS; MIRA;CARVALHO, 2001-b).

Nesse sentido, parte do programa é comum (ou igual) para todas as escolas, outra parte apresenta modalidades alternativas a adotar localmente, pelo departamento de EF ou pelo professor. Assim, os programas apresentam a seguinte configuração (ROCHA; HENRIQUES; MIRA; GUIMARÃES, 2010): i) uma parte «comum a todas as escolas", que assegura a homogeneidade do currículo real a determinado nível de desenvolvimento; ii) uma parte «alternativas a adotar localmente», que estabelece o aproveitamento de características próprias ou condições particulares presentes em cada escola.

Nesse sentido e de acordo com Rocha, Henriques, Mira e Guimarães (2010), os professores contam com os programas necessários à concretização dessas escolhas locais, mesmo tratando-se de matérias que se sabe não serem executáveis na totalidade das escolas (o caso da Natação) ou de difícil concretização (o Râguebi elementar, ou a Canoagem por exemplo) encontram-se especificadas de maneira equivalente à parte obrigatória dos programas.

Quando solicitados a indicarem sugestões para a melhoria dos programas e conteúdos da $\mathrm{EF}$, a maioria dos entrevistados referiram que se deviam criar melhores condições na escola de forma a serem introduzidas novas modalidades relacionadas com o meio sociocultural da mesma e o programa ser menos extenso, uma vez que para se cumprir o que é obrigatório, sobra pouco tempo para as modalidades alternativas.
"As escolas deviam adaptar-se para atividades radicais que há possibilidades de se realizarem com materiais ligeiros e seria mais atrativo para os alunos" E1.

"As escolas, que se encontram no litoral devem propor atividades relacionadas com o mar, são indispensáveis; no interior tudo que possa a ver com atividades de montanha..." E4.

"Para se cumprir o que é de programa obrigatório, resta pouco tempo para as modalidades alternativas onde há situações interessantes ao nível das raquetes, da dança..." E6.

É necessário que o Ministério da Educação garanta que cada escola funcione como um centro de formação e educação e que possa responder de forma diversificada às urgências locais. Se a escola quer ter uma identidade que lhe permita fornecer um contexto propício para realizar o seu projeto educativo específico, não podem continuar a existir programas, recursos e pedagogias iguais em todas as escolas (SAMPAIO, 1998).

Nesse sentido, é fundamental adaptar o programa à carga horária imposta, o que implica determinados acertos tendo em conta que o programa é bastante amplo. É igualmente importante o ajustamento do programa ao estádio de desenvolvimento e às características dos alunos (JACINTO; COMÉDIAS; MIRA;CARVALHO, 2001b), o que equivale a dizer que as normas que se apresentam, têm de proporcionar o equilíbrio e potenciar os seus pontos fortes no processo de ensino e de aprendizagem (ROCHA; HENRIQUES; MIRA; GUIMARÃES, 2010).

Ainda no contexto das alterações que se podem efetuar ao nível dos programas e 
conteúdos da EF, alguns autores (FILHO et al., 2012; MARTINS; FREIRE, 2013) têm vindo a sugerir a possibilidade de os alunos se envolverem na escolha das atividades a desenvolver nas aulas de EF. Se tal for feito, a motivação intrínseca dos alunos bem como a sua participação poderá aumentar. Tal fato, conforme referido por Filho et al. (2012), poderá ajudar os professores a escolher os conteúdos e a selecionar as estratégias mais adequadas de forma a proporcionar aulas que vão ao encontro dos interesses dos alunos. Neste sentido, e de acordo com o referido por Pinheiro, Pinto, Albuquerque e Pereira (2013, p. 93), é importante "conhecer e compreender os alunos, procurar os seus interesses e dialogar com eles, visando o seu interesse e motivação". Também Martins e Freire (2013) reforçam a ideia de que o envolvimento dos alunos na aprendizagem é fundamental, apontando para tal três elementos determinantes: o significado do conhecimento aprendido deve ser percebido pelo aluno $\square$ as atividades propostas devem ser prazerosas; o aluno deve registrar, comparar e avaliar sua própria aprendizagem. Todas as indicações apontadas por estes autores, poderão contribuir não só para o aumento do nível de interesse e participação nestas aulas, mas também para um incremento da importância que os alunos atribuem a esta disciplina

\section{A avaliação dos alunos na disciplina de EF}

De acordo com a opinião dos inquiridos, nas últimas décadas a avaliação dos alunos na disciplina de EF foi predominantemente feita através da observação direta.
"Era feita através da observação direta e com a utilização de fichas de registo" E4.

"Não havia tantos registos, era através da observação direta" E5.

"A avaliação era a olhómetro" E10.

As condições de avaliação e procedimentos de observação e recolha de dados deverão considerar os aspetos críticos do percurso de aprendizagem em cada matéria e sintetizar o grau de exigência de cada nível. A discussão e ajuste sobre o modo de olhar para os alunos em atividade, e o sistema de registo selecionado, deve ser traduzível por todos na mesma linguagem, deverão possibilitar a recolha de todas as informações que cada professor considere úteis (ROCHA; HENRIQUES; MIRA; GUIMARÃES, 2010).

A avaliação deve ser contínua e sistemática, ao longo do processo de ensino-aprendizagem para permitir ao professor reformular ou manter os objetivos selecionados e modificar, caso necessário, as estratégias utilizadas para a obtenção desses objetivos (CARVALHO; MIRA, 1993).

Questionados acerca da atual adequação da avaliação da EF aos interesses e às motivações dos alunos, os entrevistados referiram que é apropriada, porque os critérios de avaliação estão bem definidos e esta centra-se nas atitudes e na progressão do aluno.

"A avaliação é adequada, porque os professores são autónomos e são eles que decidem os critérios de avaliação, por isso tem-se em atenção os interesses dos alunos" E3.

"A avaliação centra-se de uma forma mais concisa ao nível do progresso do 
aluno ao nível da execução e da atitude" E10.

De acordo com as sugestões da maioria dos entrevistados, no futuro a avaliação deve, porém, evidenciar o empenhamento e o esforço do aluno e deve sofrer ajustamentos de acordo com as necessidades detetadas.

"Aqui são menos os resultados, mas, mais o empenho, o esforço que cada um demonstra naquilo que está a realizar, o interesse, se o aluno participa, se está atento, se traz o equipamento" E6.

"A avaliação é um trabalho que nunca acaba, porque entram professores novos para a escola trazem ideias diferentes e devem realizar-se adaptações de acordo com as necessidades" E2.

De acordo com Onofre (1996), a excelência da aprendizagem é condicionada em larga medida, pela qualidade da avaliação que se realiza. A avaliação tem que ser uma prática pedagógica e social que, antes do mais, serve para ajudar os alunos a aprender, com especial relevância para os que revelam mais dificuldades, e aos professores a ensinar através da permanente regulação dos processos associados a um desenvolvimento do currículo centrado nas realidades das escolas (FERNANDES, 2008).

A avaliação decorre dos objetivos de ciclo e de ano, os quais explicitam os aspetos em que deve incidir a observação dos alunos nas situações apropriadas. Os objetivos enunciam também, genericamente, as qualidades que permitem ao professor interpretar os resultados da observação e elaborar uma apreciação representativa das características evidenciadas pelos alunos
(JACINTO; COMÉDIAS; MIRA; CARVALHO, 2001-b).

Fernandes (2005) defende a ideia de que a avaliação deve ser parte indissociável do processo de ensino-aprendizagem, com o objetivo de informar o professor das dificuldades dos seus alunos e melhorar as suas aprendizagens.

Os critérios de avaliação estabelecidos pela escola, pelo Departamento de EF e pelo professor permitirão determinar concretamente, o grau de sucesso. Constituem, portanto, regras de qualificação da participação dos alunos nas atividades selecionadas para a realização dos objetivos e do seu desempenho nas situações de prova, expressamente organizadas pelo professor para a demonstração das qualidades visadas (JACINTO; COMÉDIAS; MIRA; CARVALHO, 2001-b).

Para apreciar as questões da avaliação é fundamental a possibilidade de adaptação às situações concretas humanas e materiais das diferentes escolas (ROCHA; HENRIQUES; MIRA; GUIMARÃES, 2010).

\section{CONCLUSÕES}

Os resultados indicam que os professores são de opinião que os alunos têm vindo a atribuir menos importância à disciplina de $\mathrm{EF}$, uma vez que se sentem, cada vez mais, atraídos por outras atividades, nomeadamente pelas novas tecnologias de comunicação e informação, e também pelo facto serem pouco envolvidos na escolha das atividades a desenvolver nas aulas de EF.

A maioria dos entrevistados mencionou que, ao contrário dos jovens, os pais e encarregados de educação davam pouca 
importância à disciplina de EF porque acreditavam estar direcionada para a diversão. Notaram porém, que atualmente, devido à competição existente no mercado de trabalho, revelam uma maior preocupação com a nota que os seus filhos possam obter nesta disciplina encontrando-se assim mais sensibilizados para o seu valor.

Segundo a opinião maioritária dos entrevistados, há ainda um longo caminho a percorrer para que ocorram melhorias significativas nos programas e nos conteúdos desta disciplina. Os programas de EF continuam orientados para atividades onde por vezes são ignorados os interesses e motivações dos alunos. Daí apontarem para o futuro algumas sugestões, nomeadamente, criar-se melhores condições nas escolas de forma a serem introduzidas novas modalidades relacionadas com o meio sociocultural e tornar os programas menos extensos.

De acordo com a opinião maioritária dos entrevistados, nas últimas décadas, a avaliação dos alunos na disciplina de EF era, predominantemente, feita através da observação direta. Atualmente é adequada e tem em conta os interesses e as motivações dos alunos. No futuro, a avaliação deve evidenciar o empenhamento e o esforço do aluno.

Temos consciência de que o presente estudo é somente um pequeno e simples contributo para o estudo desta temática. Entre as suas limitações, salientamos o número reduzido de docentes envolvidos na pesquisa. Porém, teve a virtualidade de se centrar numa cidade que apresenta um dos mais altos níveis de qualidade de vida do país. Por outro lado, as limitações do trabalho bem com os dados obtidos estimulam-nos para o desenvolvimento de futuras investigações que possam ajudar a promover e a desenvolver a disciplina da Educação Física, de modo a ultrapassar com sucesso as dificuldades e constrangimentos com que se debate, nomeadamente em Portugal.

\section{REFERÊNCIAS}

AZEVEDO, J. Sistema educativo mundial: ensaio sobre a regulação transnacional da educação. Vila Nova de Gaia: Fundação Manuel Leão, 2007.

BAILEY, R. Physical education and sport in schools: a review of benefits and outcomes. The Journal of school health, v.76, n. 8, p. 397-401, 2006.

BARDIN, L. Análise de conteúdo. Lisboa: Edições 70, 2008.

BATISTA, F. As instalações desportivas e as atividades físicas e desportivas dos alunos do ensino público obrigatório do Concelho de Braga. Estudo sobre a relação entre a legislação e a realidade. 2001. Dissertação - Faculdade de Desporto, Universidade do Porto, Porto, 2001.

BENTO, J. Contexto e Perspetivas. In: Bento, J; Garcia, R.; Graça, A. Contextos da Pedagogia do Desporto. Perspetivas e Problemáticas. Lisboa: Livros Horizonte, 1999, p. 19-112.

BENTO, J. Desporto para Crianças e Jovens: Das Causas e dos Fins. In: Gaya, A.; Marques, A.; Tani, G. Desporto para Crianças e Jovens. Razões e Finalidades. Porto Alegre: Editora da UFRGS, 2004, p. 21-56.

BENTO, J. Educação Física Escolar. As funções da Educação Física. Horizonte, v. VIII, n. 45, p. 101-107, 1991.

BETTI, M.; FERRAZ, O.; DANTAS, L. Educação Física Escolar: estado da arte 
e direções futuras. Rev. Bras. Educ. Fís. Esporte, v.25, p.105-15, 2011.

BETTI, M.; ZULIANI, L. Educação Física Escolar: uma proposta de diretrizes pedagógicas. Revista Mackenzie de Educação Física e Esporte, v.1, n. 1, p.73-81, 2002.

CARNEIRO, R. Fundamentos da Educação e da Aprendizagem. 21 ensaios para o seculo 21. Vila Nova de Gaia: Fundação Manuel Leão, 2001.

Carreiro da Costa, F. Educação física: disciplina dispensável versus disciplina imprescindível. Como ultrapassar a situação paradoxal que caracteriza a Educação Física? Revista Brasileira de Docência, Ensino e Pesquisa em Educação Física, v. 2, n. 1, p. 91-110, 2010.

CARVALHO, L.; MIRA, J. Organização e Gestão da aula de Educação Física $1^{\circ}$ ciclo do ensino básico. Horizonte, v. IX, n. 53, p. 174-176, 1993.

CONFEDERAÇÃO NACIONAL DE ASSOCIAÇÕES DE PROFISSIONAIS DE EDUCAÇÃO FÍSICA [CNAPEF]; SOCIEDADE PORTUGUESA DE EDUCAÇÃO FÍSICA [SPEF]. Matrizes curriculares 2012/2013. [Versão eletrónica]. Disponivel em: cnapef. wordpress.com/.../cnapef-e-spefdirigem-carta-as-escolas-e-aos-grup, acesso em 27 de junho de 2012.

CORTESÃO, M. Clima Escolar, participação docente e relação entre os professores de Educação Física e a comunidade. 2010. Dissertação - Universidade de Coimbra, Coimbra, 2010.

CRATO, N. Algumas ideias dominantes na educação em Portugal. In: Savater, F.; Castillo, R.; Crato, N.; Damião, H. O valor de educar, o valor de instruir.
Lisboa: Fundação F. Manuel dos Santos, 2010, p. 61-75.

CRATO, N. O "Eduquês" em discurso direto: uma crítica da pedagogia romântica e construtivista. ( $3^{\mathrm{a}}$ ed.). Lisboa: Gradiva, 2006.

CUNHA, A. Educação Física na Europa e no Brasil: um sentido comum que mostra uma identidade universal. Em Aberto, v. 26, n. 89, p. 81-93, 2013.

DARIDO, S.; RODRIGUES, H. Conteúdos na Educação Física escolar: possibilidades e dificuldades na aplicação de jogos nas três dimensões dos conteúdos. Rio Claro: UNESP, 2006.

DENZIN, N.; LINCOLN, Y. Introduction: the discipline and practice of qualitative research. In: N. Denzin \& Y. Lincoln, The Landscape of Qualitative Research. Thousand Oaks: Sage Publication, Inc., 2008, p.1-43.

EUROPEAN COMMISSION/EACEA/ EURYDICE. Physical Education and Sport at School in Europe Eurydice Report. Luxembourg: Publications Office of the European Union, 2013.

FERNANDES, D. Avaliação das aprendizagens: desafios às teorias, práticas e políticas. Lisboa: Texto Editora, 2005.

FERNANDES, D. Avaliar para aprender. São Paulo, Brasil: Ed. Unesp, 2008.

FERNANDES, M. Mudança e Inovação na Pós-Modernidade - Perspetivas curriculares. Porto: Porto Editora, 2000. FILHO, A.; TANI, G.; CORREIA, W.; CORRÊA, U. The choices made by adolescents in high school Physical Education classes: effects of grade, age, and gender on the type of ctivity. Advances in Physical Education, v. 2, n. 4, p. 163-168, 2012. 
FORMOSINHO, J.; MACHADO, J. Equipas educativas - Para uma nova organização da escola. Porto: Porto Editora, 2009.

FRAGA, A. A Perceção dos Alunos Relativamente ao Processo de Aprendizagem em Educação Física.1994. Dissertação de Mestrado, Universidade Técnica de Lisboa, Lisboa, 1994.

GHIGLIONE, R.; MATALON, B. O Inquérito. Teoria e prática $\left(4^{\mathrm{a}} \mathrm{ed}\right.$.). Oeiras: Celta Editora, 2001.

GONÇALVES, E.; CARVALHO, G. A abordagem da Saúde nos programas de Educação Física ao longo do Ensino Básico e Secundário e perspetiva de professores. In: Pereira, B.; Condessa, I.; Carvalho, G.; Cunha, C.; e Pereira, V. Atas do $\mathrm{V}^{\circ}$ Seminário Internacional//I ${ }^{\circ}$ Ibero Americano de Educação Física, Lazer e Saúde. Braga: LIBEC/CIFPEC, Universidade do Minho, 2009, p. 1-21. GRILO, E. Debate. In: Concelho Nacional da Educação- CNE. Audições Públicas no Debate Nacional sobre a Educação. Seminários e Colóquios. Lisboa: Biblioteca Nacional de Portugal - CNE, 2007, p. 134-137.

GRILO, E. Intervenções 96/99. Lisboa: Editorial do Ministério da Educação, 1999.

GUIMARÃES, A.; PELLINI, F.; ARAUJO, J.; MAZZINI, J. Educação Física Escolar: Atitudes e Valores. Motriz, v. 7, n. 1, p. 17-22, 2001.

HARDMAN, K. The situation of Physical Education in schools: a european perspective. Human Movement, v. 9, n. 1, p. 5-18, 2008.

JACINTO, J.; COMÉDIAS, J.; MIRA, J. \& CARVALHO, L. Programa de Educação Física do $3^{\circ}$ Ciclo - Reajustamento. Lisboa: Ministério da Educação, 2001-a.
JACINTO, J.; COMÉDIAS, J.; MIRA, J. \& CARVALHO, L. Programa de Educação Física $10^{\circ}, 1^{\circ}$ e $12^{\circ}$ anos. Cursos científico-humanísticos e cursos tecnológicos. Lisboa: Ministério da Educação Departamento do Ensino Secundário, 2001-b.

LOURENÇO, J. Educação Física não vai contar para a média final do secundário... [Versão eletrónica]. Dísponivel em: (www.publico.pt/ Educação/educacao-fisica-nao-vaicontar-para-a-me.). Acesso em 2 de setembro de 2012.

MacPhail, A. Youth voices in physical edcation and sport: what are they telling us and what do they say they need? In: K. Armour, Sport Pedagogy. An introduction for teaching and coaching. Essex: Pearson Education Limited, 2011, p. 105-115.

Martins, A.; Freire, E. O envolvimento dos alunos nas aulas de Educação Física: um estudo de caso. Pensar a Prática, Goiânia, v. 16, n. 3, p. 619955, jul./set. 2013. DOI 10.5216/rpp.v16i3.19222

Neto, I.; Silva, S.; Miranda, M. A produção do conhecimento referente à temática metodologia de ensino na educação física escolar: um estudo sobre os procedimentos metodológicos. Pensar a Prática, Goiânia, v. 16, n. 3, p. 619955, jul./set. 2013. DOI 10.5216/rpp. v16i3.18184

OLIVEIRA, V.; GOMES, I.; BRACHT, V. Educação para a saúde na Educação Física escolar - uma questão pedagógica! Cadernos de Formação Revista Brasileira de Ciências do Esporte, vol. 5, n², p. 68-79, 2014.

ONOFRE, M. Educação Física sem Avaliação: Uma perversão consciente? 
Boletim SPEF, n. 13, p. 51-60, 1996. PEREIRA, A. A Educação Física e Desporto em Portugal. A visão de um grupo profissionais excelentes. Parte I Panorama actual. Revista Horizonte, $\mathrm{v}$. $X X$, n. 117, Janeiro - Fevereiro, Dossier, 2005a.

PEREIRA, A. A Educação Física e Desporto em Portugal. A visão de um grupo profissionais excelentes. Parte II Panorama futuro. Revista Horizonte, v. XX, n. 118, Março - Abril, Dossier, 2005b.

PINHEIRO, M. C.; PINTO, R.; ALBUQUERQUE, A.; PEREIRA, A. "Outra vez, professor?" Percepções de alunos em relação à educação física. Motrivivência, v.XXV, n. 40, p. 90105, 2013.

PORTUGAL. Decreto-Lei n. ${ }^{\circ}$ 139/2012, de 5 de julho, Diário da República, $1 .^{a}$ série - n. ${ }^{\circ} 129,5$ de julho de 2012. p. 3476-3490.

QUINA, J. A organização do processo de ensino em Educação Física. Bragança: Instituto Politécnico de Bragança, 2009.

ROCHA, L. Parecer Professor Leonardo Rocha, coordenador das Metas de Aprendizagem de Educação Física. [Versão eletrónica]. Disponivel em: (cnapef.wordpress.com/.../parecerelaborado-pelo-professor-leonardo- rocha-coordenador-das-metas-deaprendizagem-em-educacao-fisica/). Acesso em 27 de junho de 2012.

ROCHA, L.; HENRIQUES, J.; MIRA, J.; GUIMARÃES, M. Metas de aprendizagem [Versão eletrónica], 2010. Disponivel em: (www. metasdeaprendizagem.min-edu.pt/ sobreo.../apresentação). Acesso em 30 de Junho de 2012.

SAMPAIO, D. Vivemos Livres numa Prisão. Lisboa: Editorial Caminho, SA, 1998.

SANTOS, F.; MARQUES, A.; MARTINS, J. Educação física: Que perspectivas, para que objetivos? Revista da Sociedade Científica de Pedagogia do Desporto, vol. 1, no3, p.26-32, 2014.

SHIGUNOV, V.; CARREIRO DA COSTA, F.; BRITO, J. A Relação Pedagógica em Educação Física. Influência dos Comportamentos de Afetividade e de Instrução dos Professores no Grau de Satisfação dos Alunos. Revista Brasileira de Ciências do Esporte, v. 14, n. 2, p. 71-84, 1993.

UNESCO. Diretrizes em Educação Física de Qualidade (EFQ) para gestores de políticas. Brasília: UNESCO, 2015.

VAGO, T. INÍCIO E FIM DO SÉCULO XX: MANEIRAS DE FAZER EDUCAÇÃO FÍSICA NA ESCOLA. CADERNOS CEDES, ANO XIX, No 48, P.30-55,1999. 


\title{
TEACHERS' PERCEPTIONS OF PHYSICAL EDUCATION: a case study
}

\begin{abstract}
Despite the high potential physical education has for the development of young people, it has been facing several constraints in various countries. Thus, this study has as its main goal to identify the teachers' representations about the current state of PE in a town located in central region of Portugal We conducted semi-structured interviews with 10 teachers from public schools in the municipality of Viseu - Portugal. The data showed that students have been giving less importance to the discipline while parents give more importance. Concerning the programs, the interests of students are frequently ignored. These programs should be less extensive and new subjects related to the socio-cultural environment could be promoted. Students' evaluation is adequate but in the future it should highlight students' commitment.
\end{abstract}

Keywords: Perceptions; Physical Education; Teachers, Case Study

\section{PERCEÇÕES DE LOS PROFESORES ACERCA DE LA EDUCACIÓN FÍSICA: un estudio de caso}

\section{RESUMEN}

A pesar del alto potencial de desarrollo de la juventud, la educación física se ha enfrentado muchos obstáculos en varios países. Por lo tanto, este estudio tuvo como objetivo conocer las representaciones de los profesores sobre el estado actual de EF en una ciudad en el centro de Portugal. Se llevaron a cabo entrevistas semi-estructuradas con 10 profesores, en las escuelas públicas del municipio de Viseu - Portugal. Los datos muestran que los estudiantes atribuyen menos importancia a EF mientras que los padres valoran más Los programas muchas veces ignoran los intereses de los estudiantes. Estos programas deben ser menos extensos e propocionar nuevas materias relacionadas con el entorno socio-cultural. Creer que la evaluación es actualmente adecuada y en el futuro debe destacar el compromiso del estudiante.

Palabras clave: Representaciones; Educación Física; Profesores; Estudio de Caso

Recebido em: fevereiro/2016 Aprovado em: maio/2016 